\title{
Melhoria na flexibilização e aumento de produtividade de uma linha de montagem de uma empresa do setor de autopeças através da alteração do arranjo físico do
}

\section{processo}

Improvement of the flexibility and increase of the productivity of an assembly line at an auto parts company through the change of the process layout

Mejora de la flexibilidad y aumento de la productividad de una línea de montaje en una empresa de autopartes mediante el cambio de diseño del processo

Recebido: 16/11/2021 | Revisado: 26/11/2021 | Aceito: 27/11/2021 | Publicado: 09/12/2021

\author{
Juliane Ayumi Komiya \\ ORCID: https://orcid.org/0000-0002-9463-8691 \\ Universidade Federal do Pará, Brasil \\ E-mail: juliane_ak@yahoo.com.br \\ João Nazareno Nonato Quaresma \\ ORCID: https://orcid.org/0000-0001-9365-7498 \\ Universidade Federal do Pará, Brasil \\ E-mail: quaresma@ufpa.br
}

\begin{abstract}
Resumo
Devido à competitividade entre as multinacionais nos dias atuais cada vez mais constante, essas empresas buscam intensamente a agilidade e flexibilidade em seus processos produtivos, para que consigam responder rapidamente às variações em suas demandas, eliminando os desperdícios e tornando seus processos mais enxutos e competitivos. Seguindo essa vertente, o presente trabalho teve como proposta e objetivo reestruturar o arranjo físico de uma linha de montagem convencional (arranjo linear) para células de manufatura em forma de U, e pretende-se dessa forma, obter melhoria de flexibilidade e aumento de produtividade do processo. A metodologia aplicada foi desenvolvida a partir de pesquisa bibliográfica e análise da situação atual, onde foi feito um mapeamento dos processos para identificação dos desperdícios que impactavam negativamente a linha de produção. Quanto aos fatores que impactavam negativamente o processo, foi constatada a necessidade da alteração no arranjo físico da linha de produção. Como principais resultados referentes a reestruturação, tem-se o aumento de $6 \%$ na produtividade por pessoa, redução de aproximadamente $30 \%$ na movimentação dos colaboradores no processo, e a melhoria de flexibilização da linha de montagem, adequando-se conforme a variação de demanda dos clientes.
\end{abstract}

Palavras-chave: Produção enxuta; Arranjo físico; Flexibilidade; Produtividade.

\begin{abstract}
Due to the constant competitiveness among the multinational companies nowadays, these companies intensely seek agility and flexibility in their production processes, so that they can respond quickly to variations in their demands, eliminating waste and making their processes leaner and more competitive. Following this trend, the present work had as a proposal and purpose to restructure the layout of a conventional assembly line (linear layout) for U-shaped manufacturing cells, and it is intended in this way to obtain flexibility improvement and productivity increase of the process. The applied methodology was developed from bibliographical research and analysis of the current situation, where a mapping of the processes was done in order to identify the wastes that had a negative impact on the production line. As for the factors that had a negative impact to the process, it was found that there was a need to change the layout of the production line. As the main results related to the restructuring, there is an increase of $6 \%$ in productivity per person, a reduction of approximately $30 \%$ in the movements of operators in the process, and an improvement in the flexibility of the assembly line, adapting it according to the variation in customer demand.
\end{abstract}

Keywords: Lean manufacturing; Layout; Flexibility; Productivity.

\section{Resumen}

Debido a la constante competitividad entre las empresas multinacionales en la actualidad, estas empresas buscan intensamente agilidad y flexibilidad en sus procesos productivos, para poder responder rápidamente a variaciones en sus demandas, eliminando desperdicios y haciendo sus procesos más ágiles y competitivos. Siguiendo esta tendencia, el presente trabajo tuvo como propuesta y propósito reestructurar el trazado de una línea de montaje convencional (trazado lineal) para celdas de fabricación en forma de U, y se pretende de esta forma obtener una mejora de la 
flexibilidad y un aumento de la productividad del proceso. La metodología aplicada se desarrolló a partir de la investigación bibliográfica y el análisis de la situación actual, donde se realizó un mapeo de los procesos con el fin de identificar los residuos que incidieron negativamente en la línea de producción. En cuanto a los factores que tuvieron un impacto negativo en el proceso, se encontró que existía la necesidad de cambiar el diseño de la línea de producción. Como principales resultados relacionados con la reestructuración, se observa un aumento del $6 \%$ en la productividad por persona, una reducción de aproximadamente el 30\% en los movimientos de operarios en el proceso, y una mejora en la flexibilidad de la línea de montaje, adaptándola de acuerdo con a la variación en la demanda de los clientes.

Palabras clave: Manufactura esbelta; Layout; Flexibilidad; Productividad.

\section{Introdução}

Em um mercado cada vez mais competitivo, o aumento da produtividade, a eliminação de todos os tipos de desperdícios, para reduzir custos e aumentar a lucratividade, são fundamentais para o crescimento e sobrevivência de uma empresa. As empresas sempre buscaram a alta eficiência nos processos operacionais, e as maneiras para se atingir esta eficiência sofreram mudanças ao longo dos anos.

A linha de montagem, principal característica do Fordismo, é um modelo de sistema de produção que se tornou conhecido pela busca obsessiva da alta eficiência. As principais características deste tipo de sistema são: grandes lotes e pequena variedade de produtos, onde se lucra pela escala de produção; linhas de montagem e operadores especialistas; produção empurrada; inflexibilidade e estoques elevados (Womack et al., 1992).

Com as novas necessidades do mercado, os produtos se tornaram mais diversificados e complexos, e também passaram a sofrer mudanças de forma cada vez mais rápida. Diante deste novo cenário, surgiu um novo modelo de sistema de produção, que ficou conhecido como produção enxuta (Antunes et al., 2008). Suas principais características são: redução de custos por meio da eliminação dos desperdícios; produção puxada; melhoria de qualidade; melhoria contínua; envolvimento das pessoas nos processos; flexibilidade e nível de estoque reduzido (Yamamoto et al., 2019).

A produção enxuta é considerada um sistema de produção extremamente flexível às variações de demanda, proporcionando alta qualidade e rapidez de resposta. Contempla princípios e ferramentas que contribuem para o desenvolvimento de vantagem competitiva para as empresas que adotam esta filosofia, a qual envolve práticas voltadas à melhoria da qualidade, inovação, produção puxada, redução de estoques, que permitem identificar as deficiências do processo de forma que elas possam ser minimizadas ou eliminadas, e com isso, ter uma produção mais enxuta e mais eficiente (Trentin, 2017).

Uma das ferramentas da produção enxuta, o trabalho padronizado, consiste em definir a maneira mais segura, simples e eficiente de se desempenhar uma tarefa, e tem como objetivo aumentar a produtividade através do balanceamento da linha ao longo de todo o processo e redução da variabilidade, resultando em um processo padronizado e estável (Fin et al., 2017).

O estudo que será apresentado neste trabalho tem como objetivo obter melhoria de flexibilidade e aumento de produtividade em uma linha de montagem de uma empresa de manufatura, através de uma proposta de alteração de arranjo físico, de um sistema de produção com arranjo linear para arranjo físico em U. Diante da crise política e econômica vivida pelo país, que vem ocasionando uma queda acentuada nas vendas, a empresa busca uma forma de se adequar a este novo cenário, ganhando flexibilidade em seu processo produtivo que permita a empresa responder rapidamente às variações de demanda dos clientes, sem que haja aumento de custos. Para isso, a empresa iniciou uma análise da situação atual e identificou alguns desperdícios, principalmente relacionados a movimentação de operadores dentro do processo e ao desbalanceamento entre os processos, e observou que grande parte deles estava condicionado ao arranjo físico de sua linha de montagem. Diante disso, foi elaborada uma proposta de melhoria baseada em alteração de arranjo físico do processo produtivo, com o objetivo de eliminar os desperdícios identificados e assim ter uma linha mais enxuta e competitiva. 


\section{Revisão da literatura}

\subsection{Surgimento da produção enxuta}

Na primeira metade do século XX, Henry Ford inovou a indústria automobilística quando desenvolveu um sistema denominado de produção em massa, cuja principal característica são as linhas de montagem, com operações segmentadas e distribuídas entre os montadores, de forma que cada um execute uma única tarefa. Este modelo de produção trouxe um grande aumento de produtividade, e permaneceu por mais de meio século como a forma mais eficiente de montagem (Womack et al., 1992).

No entanto, alguns pontos negativos se tornaram evidentes. A necessidade de produzir grandes volumes para minimizar os custos de produção e obter lucro, gerava falta de flexibilidade da linha e acarretava em estoques elevados que muitas vezes escondiam defeitos entre as peças produzidas. Outro ponto negativo era a limitação de conhecimento dos montadores sobre a influência de suas operações no produto final, uma vez que as operações realizadas por cada um foram divididas aos menores elementos possíveis (Womack et al., 1992).

Ao longo dos anos, os consumidores passaram a escolher os modelos, e a comprar a opção que mais lhe agrada dentre as possibilidades oferecidas pelos fabricantes, exigindo uma maior variedade de produtos. Para as empresas se manterem competitivas neste cenário, tornou-se necessário produzir lotes cada vez menores e produtos cada vez mais diferenciados, além de garantir preços compatíveis, qualidade intrínseca e prazos de entrega razoáveis. Neste novo tipo de concorrência, diante das novas necessidades do mercado, Taiichi Ohno viu a oportunidade para novas formas de gestão da produção, o que levou à rápida difusão no Japão de sistemas de produção como o Sistema Toyota de Produção (STP) (Antunes et al., 2008).

Na década de 1950, quando Ohno visitou a fábrica da Ford nos Estados Unidos, verificou que a produção de grandes volumes resultava em acúmulos de materiais (Bellato \& Mazzonetto, 2021), e concluiu que o planejamento de produção não deve ser ditado por metas de quantidades a serem produzidas, e sim baseado no volume efetivamente vendido, para que não haja produção em excesso, algo que precisava ser evitado diante da precária situação financeira vivida pelo Japão pós-guerra. Assim surgiu o conceito de produção puxada pela demanda do cliente, um dos princípios do TPS, no lugar da produção empurrada por metas. Além do excesso de produção, Ohno identificou outros seis tipos de desperdícios que devem ser eliminados, e o TPS se tornou um dos maiores precursores da produção enxuta (Yamamoto et al., 2019).

A filosofia da produção enxuta visa aumentar a eficiência e a produtividade de um processo, sem que haja prejuízo na qualidade ou investimentos elevados, reduzindo custos e o tempo de entrega, por meio da eliminação de desperdícios e do envolvimento de toda a organização (Womack \& Jones, 2003). A meta da filosofia enxuta é aprimorar o desempenho organizacional em todos os níveis operacionais através da eliminação de todos os tipos de atividades desnecessárias e que não agregam valor (Dave, 2020).

Diferentemente do estilo desenvolvido na produção em massa, as técnicas aplicadas na produção enxuta consistem em aumentar a qualidade e a satisfação dos clientes, e obter a máxima eficiência econômica com o mínimo de recursos possível (Yamamoto et al., 2019).

\subsubsection{Tipos de desperdícios}

Produção enxuta é um sistema de produção que considera o emprego de recursos para o atingimento de metas ou para criação de valores. Do ponto de vista do cliente, "valor" pode ser definido como sendo o preço pelo qual o cliente está disposto a pagar. O ponto chave da manufatura enxuta está na eliminação de todos os tipos de desperdícios (Dave, 2020).

O desperdício é qualquer atividade humana que não agrega valor. Pinto (2014) acrescenta ainda, que é qualquer tipo de recurso utilizado de maneira errada, que acarreta em aumento de custos, de tempo e da não satisfação das partes interessadas no negócio, especialmente dos clientes. Estas atividades consomem tempo e recursos, gerando um custo adicional 
sobre os produtos ou serviços, pelo qual não se terá retorno. Organizações concorrentes que conseguem entregar o mesmo produto ou serviço em menos tempo ou a um preço menor têm vantagem competitiva no mercado.

Sete tipos de desperdícios foram identificados por Ohno (Liker, 2005; Oliveira et al., 2017).

1. Excesso de produção: fabricação de grandes lotes de peças sem que haja demanda, gerando desperdício de tempo e o risco de camuflar peças com defeito;

2. Espera: ocorre quando um processo precisa esperar por algo para que a tarefa possa ser executada;

3. Transporte: movimentação de peças, material em processo ou produtos acabados, além do necessário;

4. Processamento em excesso: desperdícios causados pela execução de processos incorretos ou desnecessários, ou seja, a execução de processos que, do ponto de vista do cliente, não agregam valor ao produto;

5. Movimento: qualquer movimento que uma pessoa executa, que não esteja agregando valor ao processo;

6. Estoques: materiais parados que demandam área e outros tipos de recursos para seu armazenamento e gerenciamento, estão sujeitos a sofrer danos ou se tornarem obsoletos, e podem ainda esconder problemas de qualidade.

7. Retrabalho: qualquer processo, produto ou serviço que não atenda as especificações, ou qualquer processamento que não transforma o produto ou não é executado da forma correta na primeira vez.

Dentre os desperdícios identificados pelo STP, o que representa a perda mais relevante é o excesso de produção, pois este pode desencadear grande parte dos outros desperdícios, tais como estoques, transporte, movimento, retrabalho. Em qualquer etapa da produção, produzir em quantidades maiores do que a demanda do cliente ou com excesso de antecipação, acarretará em estoques intermediários aguardando processamento ou ainda em estoques de produto acabado aguardando a venda (Liker \& Meier, 2007).

\subsection{O tempo takt e o tempo de ciclo}

Tempo takt é o tempo necessário para se produzir um componente ou um produto, levando em consideração a demanda do cliente e o tempo disponível para produção. Matematicamente é dado pela razão entre o tempo disponível para a produção, subtraindo-se as paradas planejadas, e a quantidade que precisa ser produzida para atender a demanda do período (Shingo, 2005). Em outras palavras, Alvarez e Antunes (2001) definem tempo takt como sendo o ritmo de produção necessário para atender a uma determinada demanda, onde este ritmo é limitado pela capacidade da linha de produção.

Já o tempo de ciclo em um sistema de produção representa o ritmo máximo possível, e depende das condições de operação da célula ou linha. O tempo de ciclo é o tempo decorrido entre o início e o término de um ciclo, caracterizado pela repetição de uma mesma operação. Em uma célula ou linha de produção com mais de um posto de trabalho, o tempo de ciclo depende do tempo de processamento em cada posto de trabalho e do número de operadores na célula ou linha (Antunes, 2008).

Em um sistema de produção, o tempo de ciclo é um limitante do tempo takt, uma vez que, se o tempo de ciclo for maior do que o tempo takt, não haverá capacidade de produção suficiente para atender a demanda. O ritmo de uma linha é sempre limitado, ou pela capacidade (representada pelo tempo de ciclo) ou pela demanda (representada pelo tempo takt) (Alvarez \& Antunes, 2001).

Uma vez definido o tempo takt, a meta é ajustar cada uma das operações de tal forma que todas elas sejam executadas exatamente no tempo takt. Isto pode ser feito através do desenvolvimento preciso do trabalho padronizado, onde cada aspecto da operação é cuidadosamente analisado e otimizado, e cada operação é executada todas as vezes da mesma maneira, exatamente conforme o padrão (Suri, 1998). 


\subsection{Trabalho padronizado}

Dentro da filosofia enxuta, o trabalho padronizado é um princípio utilizado para estabelecer um padrão para se executar determinada tarefa da melhor forma, eliminando os desperdícios, reduzindo a variabilidade e focando em operações que agregam valor (Coimbra, 2013).

O trabalho padronizado consiste em estabelecer procedimentos exatos para o trabalho de cada um dos operadores em um processo produtivo, com base em três elementos, que são (Lean Enterprise Institute, 2011):

- Tempo takt: taxa em que os produtos devem ser produzidos de forma a atender à demanda do cliente;

- Sequência de produção: melhor sequência de operações para executar uma tarefa dentro do tempo takt;

- Estoque padrão: quantidade de estoque em processo necessário para garantir um fluxo de produção sem interrupção.

O trabalho padronizado tem como objetivos, a estabilização dos processos através da eliminação das fontes de variação, o balanceamento da carga de trabalho, e a manutenção da qualidade por meio de criação de rotinas. A distribuição das atividades dos operadores em relação ao tempo takt é determinada através da identificação dos elementos do trabalho e da eliminação das operações e processos que não agregam valor (Oliveira e Figueiredo, 2018).

A padronização dos processos permite eliminar os desperdícios através de melhorias simples no cotidiano, tais como mudar a posição de uma ferramenta ou de um equipamento, alterar a forma de alimentação da linha, encurtar a distância para minimizar a movimentação de pessoas e materiais, etc. (Shingo, 2005).

Uma vez implantado e exposto nas estações de trabalho, o trabalho padronizado serve como ferramenta de melhoria contínua, possibilitando ter um processo documentado e padronizado, redução da variabilidade e facilidade no treinamento de novos operadores.

\subsection{Arranjo físico}

O arranjo físico é a disposição de máquinas, pessoas, postos de trabalho, área de armazenamento de estoques, e todos os recursos necessários para a produção. Um arranjo físico planejado de forma estratégica é fundamental para uma organização obter vantagem competitiva (Corrêa \& Corrêa, 2017).

A finalidade do arranjo físico é simplificar as operações. Com um arranjo físico adequado, a empresa consegue otimizar os recursos utilizados, minimizando a distância percorrida na movimentação de materiais e pessoas, o que reflete também em maior flexibilidade, aumento da produtividade e melhoria da qualidade (Santos \& Volante, 2020).

Podem ser citados como sendo os principais objetivos do arranjo físico de uma linha de produção, o uso eficiente de pessoas, equipamentos, espaço e recursos; proporcionar facilidade, conforto e segurança aos operadores; flexibilidade operacional para atendimento da demanda dos clientes; aumento da capacidade produtiva; eliminação de desperdícios de movimentos desnecessários; redução do tempo de ciclo; melhoria da qualidade por meio do controle visual das atividades do processo produtivo (Bellato \& Mazzonetto, 2021).

Para atender as diversas necessidades das organizações, podem ser identificados basicamente quatro tipos de arranjos físicos, que podem ainda ser combinados entre si: (i) arranjo físico por processo, que agrupa pessoas e máquinas que desempenham funções semelhantes; (ii) arranjo físico por produto, onde os recursos são posicionados de acordo com a sequência das etapas de fabricação do produto; (iii) arranjo físico celular, em que os recursos similares são agrupados para processar um grupo de itens com características similares; (iv) arranjo físico posicional, onde os recursos se deslocam até o objeto da operação que fica parado (Slack et al., 2009).

Suri (1998) define a célula de manufatura como sendo um conjunto de máquinas ou recursos dispostos próximos uns aos outros, de acordo com o processo do produto, de forma a minimizar a movimentação de peças. Um arranjo físico em formato de U pode ser utilizado para minimizar a movimentação de operadores, uma vez que o início e o final do processo 
ficam próximos.

$\mathrm{O}$ arranjo físico em formato de $\mathrm{U}$ pode ser operado de três formas: (i) operações divididas entre os operadores, onde cada operador fica responsável por executar uma parte do processo, tendo como desvantagem a dificuldade de balanceamento das operações; (ii) um único operador realizando todas as operações, passando por todos os postos, não havendo neste caso a necessidade de balanceamento das operações, porém, sua desvantagem é o tempo de treinamento mais longo, já que o operador precisa aprender o processo todo; (iii) mais de um operador, com cada um realizando todas as operações, com dois ou mais operadores passando por todos os postos, onde a principal vantagem é a maior flexibilidade para se ajustar a capacidade de produção de acordo com a variação da demanda, porém, uma desvantagem é que o tempo de ciclo é ditado pelo operador mais lento (Suri, 1998).

Este último caso é conhecido também como caça ao coelho (rabbit chase), onde as operações são conduzidas através de uma peça por vez, passando por todo o processo sem acumular estoques intermediários entre os processos. Neste caso, um operador é visto como a caça de outro. Uma das maiores vantagens do arranjo físico em forma de U é o ganho de flexibilidade que permite responder rapidamente às variações de demanda, evitando perdas com balanceamento de linha (Suzaki, 1987).

Outro mérito que se observa é o aumento da motivação e autoestima do colaborador, que se sente "dono da linha", e tem maior comprometimento com a produção e a qualidade do produto que está montando, pois executa todas as operações do início ao fim, até chegar ao produto acabado. Além disso, tem-se colaboradores multifuncionais que sabem executar todas as operações e conhecem o produto que está montando, e não apenas uma pequena parcela do processo. Com isso, este conhecimento dos operadores também pode ser aproveitado para realizar melhorias no processo, estimulando os próprios operadores a expor suas opiniões e ideias (Suzaki, 1987).

\subsection{Aplicações do trabalho padronizado}

Por meio da reavaliação do trabalho padronizado em uma linha de montagem de uma indústria automotiva, Oliveira e Figueiredo (2018) identificaram desperdícios padronizados dentro do processo produtivo, e com o novo balanceamento, foi possível obter um aumento de produtividade de $29 \%$, sem prejudicar a estabilidade dos indicadores de qualidade e segurança.

Em uma empresa do setor de implementos agrícolas, Anselmo et al. (2020) aplicaram o trabalho padronizado em uma célula de manufatura, e por meio do desenvolvimento de um plano de ação baseado na filosofia enxuta e da análise dos impactos com a aplicação do trabalho padronizado, conseguiram atingir todas as metas de indicadores estabelecidas pela empresa, e o estudo permitiu ainda identificar e minimizar atividades que geram desperdício, tornar o fluxo do processo mais claro e facilitar os treinamentos operacionais.

Silva et al. (2019) obtiveram êxito em alcançar as metas estabelecidas, ao desenvolverem uma análise do mapeamento de fluxo de valor e implantarem o programa $5 \mathrm{~S}$ e a padronização do trabalho em uma fábrica de colchões. A aplicação das ferramentas da manufatura enxuta não só trouxe o aumento de $20 \%$ na produtividade diária, e uma redução de $90 \%$ no índice de movimentação, mas também foi responsável por promover melhorias na qualidade de vida dos trabalhadores e o aumento do índice de satisfação dos clientes.

Freitas e Silva (2017) descreveram e analisaram criticamente a implementação do trabalho padronizado em uma célula de manufatura de uma fábrica de tratores, onde havia desbalanceamento e não atendimento da demanda diária. As ações desenvolvidas e adotadas para padronização das operações trouxeram como resultados a redução de $40 \%$ das atividades que não agregam valor, redução da taxa de erros em 17\%, 50\% de redução de estoque em processo, e $20 \%$ de aumento de produtividade.

Em um estudo de caso desenvolvido em uma linha de montagem de chassis, Fin et al. (2017) demonstram os resultados positivos alcançados por meio da implementação do trabalho padronizado, cujas etapas se mostraram eficazes, tendo 
possibilitado reduções de $15 \%$ no tempo de ciclo, $34,5 \%$ nos movimentos dos operadores, e 9,6\% de paradas de linha. Os autores reforçam ainda que o trabalho padronizado tem como base o comprometimento das pessoas envolvidas, e depende da continuidade do trabalho pela equipe na eliminação de erros e desperdícios, em busca da excelência de manufatura.

\section{Estudo de Caso}

\subsection{Caracterização da empresa}

$\mathrm{O}$ estudo de caso foi desenvolvido na empresa "A", uma empresa multinacional que atua no setor de autopeças voltado a duas rodas, e opera no Polo Industrial de Manaus. Atualmente trabalham na empresa, aproximadamente 300 funcionários, sendo $60 \%$ mão de obra direta e $40 \%$ mão de obra indireta. Para serviços de conservação e limpeza da área da fábrica, utiliza mão de obra terceirizada. A empresa produz basicamente três tipos de peças para motocicletas: produto $\mathrm{S}$, produto $\mathrm{R}$ e produto $\mathrm{E}$.

Atualmente a empresa trabalha em linhas de montagem, porém, para acompanhar as mudanças do mercado e se adequar a recente queda acentuada nas vendas, a empresa "A" busca novas formas de produção, alterando, para alguns produtos, o arranjo físico de seu processo produtivo. Com isso a empresa espera ganhar flexibilidade para responder rapidamente às variações de demanda, e aumentar a produtividade.

A empresa estudada produz três produtos distintos para motocicletas, não sendo possível, neste trabalho, abranger o processo de fabricação de todos os produtos. Portanto, o estudo será restrito a um tipo de produto, montado em uma das linhas da fábrica.

A empresa opera em um turno, sendo o regime de trabalho de 8,6 horas de segunda a quinta, e 7,6 horas na sexta, já desconsiderando os intervalos da produção. Calculando a média das horas de segunda à sexta, resulta em um tempo disponível de 8,4 horas por dia.

\subsection{Universo e amostra}

Por motivos de confidencialidade, as informações como nome da empresa, nomes dos produtos e dos processos, serão apresentados sob nomes fictícios. Conforme mencionado acima, este estudo se concentrou em apenas uma linha de montagem, do produto R, que contém seis processos, sendo cinco processos de montagem e um processo de inspeção final.

A demanda diária do produto R é de 940 peças. Com o tempo disponível de 8,4 horas ou 30240 segundos, tem-se um tempo takt de 32,2 segundos por peça.

\subsection{Metodologia}

A classificação da pesquisa quanto aos fins define o tipo de pesquisa de acordo com o resultado final ou objetivo geral, que o pesquisador busca alcançar através da realização da pesquisa (Vergara, 2000). Este trabalho consiste em uma pesquisa aplicada, a qual busca solucionar um problema concreto e prático. Para Marconi e Lakatos (1999), a pesquisa aplicada tem interesse prático, pois seus resultados são utilizados diretamente na solução de problemas da realidade. Em uma pesquisa aplicada, o objetivo é identificar a situação-problema e buscar, dentre as possíveis soluções, aquela que possa ser mais adequada para o contexto, aplicando conhecimentos já existentes.

A classificação da pesquisa quanto aos meios aprofunda a classificação quanto aos fins, e representa uma forma mais completa de determinar como a pesquisa será realizada (Vergara, 2000). Quanto aos meios, este trabalho é classificado como um estudo de caso, onde se pretende analisar a situação atual de um processo produtivo identificando os principais problemas, e propor uma alteração de arranjo físico.

Para se alcançar os objetivos, foi feita a organização de todos os dados, principalmente aqueles mais relevantes para 
evidenciar os méritos das atividades alcançados com as melhorias implantadas. As ferramentas utilizadas para evidenciar os resultados foram através de cronoanálise e gráficos, fazendo um comparativo antes e após a implantação das melhorias.

Para se ter um melhor entendimento do desenvolvimento deste trabalho e da metodologia adotada, foi incialmente feita uma análise da situação atual, aplicação da ferramenta de análise de perdas e em seguida a verificação dos resultados.

\subsubsection{Análise da situação atual}

Com o objetivo de se ter conhecimento do cenário atual, foi feito um levantamento de todas as anormalidades em todos os processos, evidenciando os principais desperdícios. Através da ferramenta de análise de perdas, em conjunto com as informações levantadas, foram planejadas as melhorias e feitas as simulações para se alcançar os objetivos.

\subsubsection{Aplicação da ferramenta de análise de perdas}

Esta ferramenta foi utilizada internamente na empresa em estudo, e teve como principal objetivo mapear todas as operações desempenhadas em cada processo, estratificando o manuseio de peças, tempo de movimentação do colaborador com ou sem peça, e tempo de ciclo de máquina. Com estas informações, foi possível verificar a condição atual e fazer simulações de propostas de melhorias, tendo como parâmetros a redução de desperdícios e o aumento de produtividade. As etapas da ferramenta para se alcançar os objetivos são apresentadas no fluxograma mostrado na Figura 1.

Figura 1 - Fluxograma da ferramenta de análise.

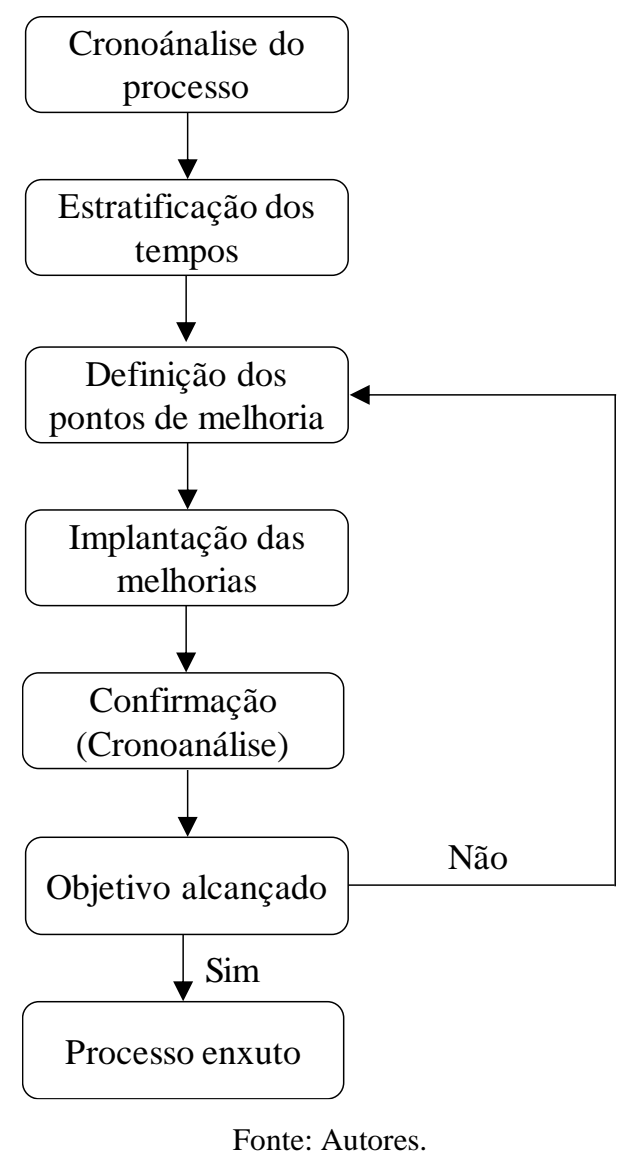

De acordo com as informações acima, cada etapa do fluxograma tem um objetivo, conforme descrito a seguir. 


\subsubsection{Cronoánalise do processo}

Nesta etapa foi feita a análise do tempo de ciclo de máquina e do tempo de movimentação dos colaboradores no processo produtivo. Com o objetivo de aumentar a acuracidade dos dados, a cronoánalise foi conduzida fazendo-se a repetibilidade de no mínimo 15 vezes, e em seguida foi calculada a média dos valores para ser considerado no estudo. Além disso, esta análise foi realizada em horários distintos e com diferentes colaboradores.

\subsubsection{Estratificação dos tempos}

Para um melhor entendimento da influência de cada tempo no processo, foi feita a separação dos tempos de ciclo de máquina, tempo de ciclo do processo e os tempos de movimentação dos colaboradores, pois desta forma facilita a tomada de ações nos pontos que requerem melhorias ou até mesmo a eliminação de anormalidades e principalmente de desperdícios.

\subsubsection{Definição dos pontos de melhorias}

Após a estratificação dos tempos, foi possível visualizar os pontos que precisavam de tomada de ações. Para este estudo, os pontos de melhorias tiveram como enfoque maior as movimentações dos colaboradores nos processos, priorizando as movimentações que não agregam valor ao produto, ou seja, consideradas desperdício. Após esta definição foi estabelecido um objetivo a ser alcançado.

\subsubsection{Implantação das melhorias}

Nesta etapa foram implementadas ações para eliminar ou reduzir os pontos que precisavam de melhorias. Neste estudo, antes da implementação, foram feitas simulações para se identificar a melhoria mais relevante a ser implantada. Foi levado em consideração a melhor concepção de arranjo físico que proporcionasse flexibilidade para adequar o processo conforme a variação da demanda do cliente, e conseguir produzir com o mínimo de desperdícios possíveis.

\subsubsection{Confirmação (Cronoanálise)}

Após a implementação das ações foi realizada novamente uma cronoánalise do processo a fim de confirmar a eficácia das ações. Esta análise foi feita de forma similar à realizada na primeira etapa.

\subsubsection{Objetivo alcançado}

Foram considerados como satisfatórias as ações que alcançaram resultado igual ou acima do que foi planejado. Caso contrário, deve-se refazer a definição de novos pontos de melhorias no processo, com o objetivo de alcançar os resultados planejados.

\subsubsection{Processo enxuto}

Foi considerado como critério para o processo enxuto, a eliminação ou a redução das movimentações que não agregam valor ao produto. Outro ganho foi a redução do espaço físico ocupado pelo processo e consequentemente a redução na distância das movimentações necessárias dos colaboradores.

\subsubsection{Verificação dos resultados}

Para verificação dos resultados foram utilizados como os principais parâmetros, o tempo de caminhada dos colaboradores nos processos produtivos e a quantidade de peças produzidas por colaborador. 


\section{Resultados e discussão}

\subsection{Análise da situação atual}

O produto R era produzido em uma linha de montagem de arranjo físico linear, com três operadores e seis processos, considerando a inspeção final. A Figura 2 mostra a configuração atual da linha e o fluxo de operadores. As setas na cor azul indicam os movimentos de deslocamento dos operadores de um posto para outro. A linha contínua se refere ao movimento de ida, quando o operador caminha de um posto ao outro processando a peça. Já a linha tracejada indica o movimento de retorno do operador ao processo inicial após concluir o ciclo de operação. Essas linhas tracejadas são consideradas movimentos em que o colaborador não está processando peças, portanto não agregam valor ao produto, porém eram necessárias devido a concepção do arranjo físico conforme abaixo.

Figura 2 - Arranjo físico linear.

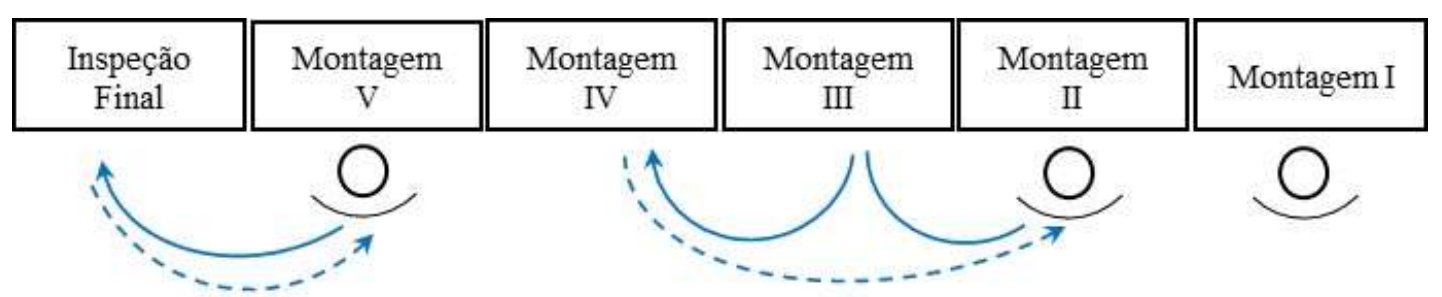

Fonte: Autores.

Analisando a concepção do arranjo físico atual de maneira mais precisa, foi possível perceber que existiam muitos desperdícios quando se referia a movimentação dos colaboradores de um posto para o outro, e além disso, os tempos de ciclo apresentavam desbalanceamento entre os colaboradores, ocasionado pela concepção do arranjo físico do processo de montagem. Todas essas informações foram apresentadas no Quadro 1, que mostrou a análise de forma estratificada do tempo de cada operação e movimentação durante o processamento das peças. 
Research, Society and Development, v. 10, n. 16, e124101623403, 2021

(CC BY 4.0) | ISSN 2525-3409 | DOI: http://dx.doi.org/10.33448/rsd-v10i16.23403

Quadro 1 - Ferramenta de análise de perdas em arranjo físico linear.

\begin{tabular}{|c|c|c|c|c|c|}
\hline \multicolumn{6}{|c|}{ Folha de Distribuição Padrão } \\
\hline \multicolumn{3}{|c|}{ Linha: Montagem do Produto R } & \multicolumn{3}{|c|}{$\begin{array}{l}\text { Demanda diária: } 940 \text { pes } \\
\text { Tempo disponível: } 8,4 \mathrm{~h} \quad(30240 \mathrm{~s})\end{array}$} \\
\hline \multicolumn{2}{|c|}{ Quantidade de operadores: } & 3 & Tempo takt: & $32,2 \mathrm{~s}$ & \\
\hline \multirow{2}{*}{ Operador } & \multirow{2}{*}{ Processo } & \multirow{2}{*}{ Operação } & \multicolumn{3}{|c|}{ Tempo (segundos) } \\
\hline & & & Manual & Máquina & Caminhada \\
\hline \multirow{6}{*}{ Operador 1} & \multirow{6}{*}{ Montagem I } & 1. Encaixar a peça $\mathrm{Cl}$ no dispositivo & 0.9 & & \\
\hline & & 2. Encaixar a peça $\mathrm{C} 2$ no dispositivo & 1.1 & & \\
\hline & & 3. Montar componentes $\mathrm{i}, \mathrm{j}, \mathrm{k}$ na peça $\mathrm{C} 1$ & 7.0 & & \\
\hline & & 4. Montar componentes $1, \mathrm{~m}, \mathrm{n}$ na peça $\mathrm{C} 2$ & 8.3 & & \\
\hline & & 5. Inserir componente $\mathrm{T} 1$ & 1.7 & & \\
\hline & & 6. Retirar a peça montada do dispositivo & 1.5 & & \\
\hline \multirow{15}{*}{ Operador 2} & \multirow{5}{*}{ Montagem II } & 1. Encaixar a peça G1 no dispositivo & 0.8 & & \\
\hline & & 2. Inserir os componentes $\mathrm{i}, \mathrm{j}, \mathrm{k}, \mathrm{l}, \mathrm{m}$ na peça $\mathrm{Gl}$ & 2.2 & & \\
\hline & & 3. Acionar alavanca do dispositivo & 0.8 & 1.1 & \\
\hline & & 4. Retirar a peça montada do dis positivo & 0.9 & & \\
\hline & & 5. Inserir componente $\mathrm{T} 2$ & 1.0 & & 1.6 \\
\hline & \multirow{4}{*}{ Montagem III } & 1. Encaixar a peça G2 no dispositivo & 0.8 & & \\
\hline & & 2. Inserir os componentes $\mathrm{i}, \mathrm{j}, \mathrm{k}, \mathrm{l}, \mathrm{m}$ na peça $\mathrm{G} 2$ & 1.7 & & \\
\hline & & 3. Acionar alavanca do dispositivo & 0.8 & 1.1 & \\
\hline & & 4. Retirar a peça montada do dispositivo & 1.1 & & 1.8 \\
\hline & \multirow{6}{*}{ Montagem IV } & 1. Montar componente T3 no componente n & 0.9 & & \\
\hline & & 2. Montar peça $\mathrm{R}$ no componente $\mathrm{n}$ & 2.0 & & \\
\hline & & 3. Colocar a peça montada no dispositivo & 0.8 & & \\
\hline & & 4. Prensar componente y & & 1.0 & \\
\hline & & 5. Retirar a peça montada do dispositivo & 0.9 & & \\
\hline & & 6. Ajustar posição da peça $\mathrm{R}$ & 1.5 & & 4.2 \\
\hline \multirow{10}{*}{ Operador 3} & \multirow{4}{*}{ Montagem V } & 1. Ajustar posição das peças G1 e G2 & 7.1 & & \\
\hline & & 2. Aplicar componente f & 4.8 & & \\
\hline & & 3. Inserir componente $\mathrm{T} 4$ & 0.9 & & \\
\hline & & 4. Inserir componente T5 & 1.4 & & 1.6 \\
\hline & \multirow{6}{*}{$\begin{array}{c}\text { Inspeção } \\
\text { Final }\end{array}$} & 1. Encaixar peça no dispositivo & 0.8 & & \\
\hline & & 2. Conectar os componentes i, j, k no dispositivo & 1.0 & & \\
\hline & & 3. Realizar o teste & & 0.8 & \\
\hline & & 4. Conectar os componentes $1, \mathrm{~m}$ no dispositivo & 0.8 & & \\
\hline & & 5. Realizar o teste & & 0.8 & \\
\hline & & 6. Retirar a peça do dispositivo & 1.3 & & 1.8 \\
\hline
\end{tabular}

Fonte: Autores.

Por meio da ferramenta apresentada no Quadro 1, foram identificados os tempos de caminhada dos operadores, e grande parte dessa movimentação não estava agregando valor ao produto, ou seja, eram movimentos considerados desperdício. A distribuição de atividades acima era feita com 3 operadores, pois esta era a quantidade necessária para que a empresa conseguisse atender a demanda diária dos clientes, que naquele período era de aproximadamente 940 peças por dia. Porém, após uma verificação mais detalhada, os dados coletados na análise foram apresentados na Figura 3, onde foi possível observar que diariamente existia uma ociosidade, ou seja, a capacidade produtiva com 3 operadores estava aproximadamente 15\% acima da demanda dos clientes. Na tentativa de minimizar ou até mesmo eliminar a ociosidade existente, foram realizados testes com 2 e 1 operadores, no entanto, percebeu-se que desta forma não seria possível atender a demanda diária dos clientes, conforme mostrado abaixo. 
Figura 3 - Produtividade antes da alteração.

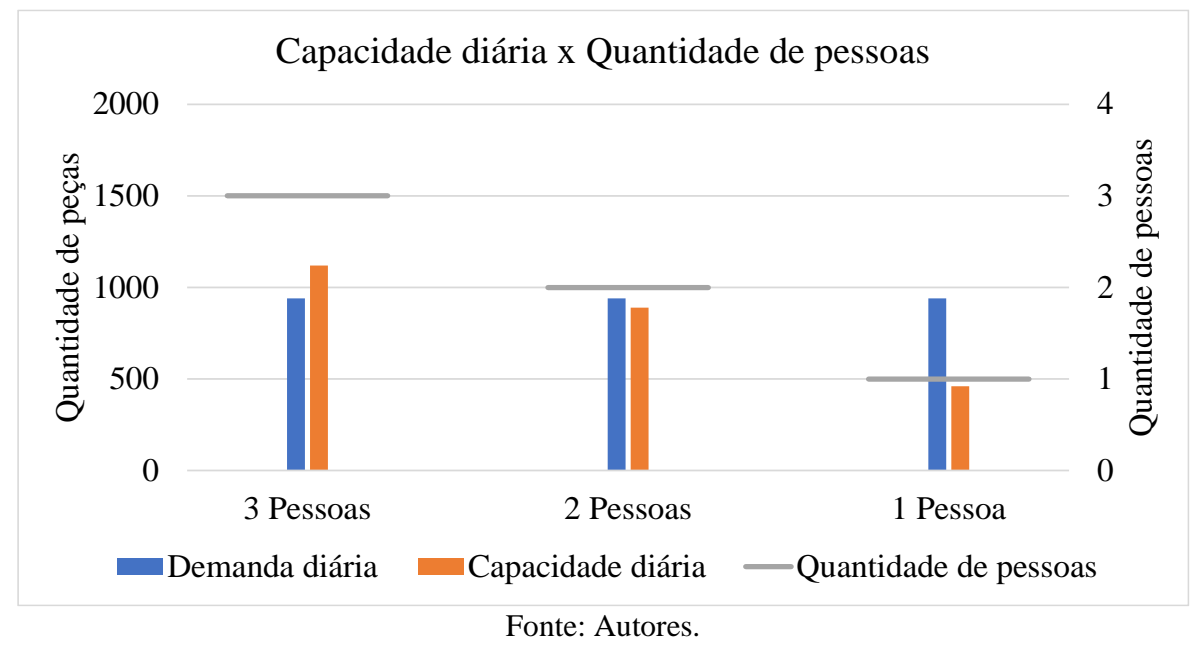

Na Figura 3 é possível observar que, com a redução de pessoas para 2 ou 1 no processo, não era possível atender a demanda dos clientes, e quando se utilizavam 3 colaboradores, existia ociosidade. Diante dessa dificuldade, onde não era possível reduzir a demanda dos clientes, porém aumentar a quantidade de pessoas no processo seria um custo adicional, percebeu-se que o arranjo físico da linha de montagem não estava adequado para absorver as variações de demanda dos clientes, ou seja, era uma concepção de linha onde não havia flexibilidade. Além disso, existia dificuldade para balancear o tempo entre os processos, pois conforme se reduzia a quantidade de pessoas na linha de montagem, ocorria um aumento de movimentação que não agregava valor ao produto e também uma queda de produtividade. Como consequência, aumentavam os desperdícios que tornavam o processo de fabricação menos competitivo.

\subsection{Proposta de melhoria}

Com base nos problemas e dificuldades que estavam ocorrendo, a proposta de melhoria do arranjo físico levou em consideração principalmente os fatores preponderantes como: a minimização de movimentações que não agregavam valor ao produto, e o ganho de flexibilidade da linha, que permitisse aumentar ou reduzir a quantidade de pessoas no processo sem que houvesse aumento de movimentação desnecessária. Esses desafios nortearam todo o estudo de melhoria do processo, e para atender as exigências acima, a concepção de arranjo físico que mais se adequou foi em formato de U, conforme mostrado na Figura 4, uma vez que esta concepção permitiu encurtar a distância percorrida pelos operadores, e principalmente, reduzir a movimentação que não agrega valor ao produto.

Figura 4 - Arranjo físico com formato em U.

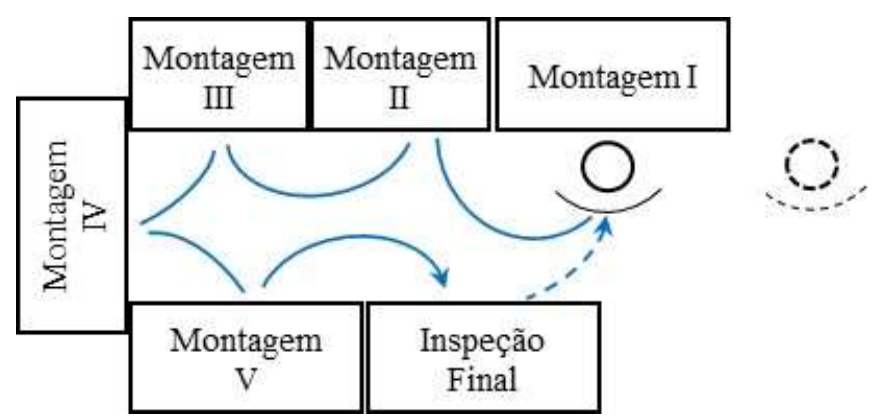

Fonte: Autores. 
Pela concepção de arranjo acima, o operador sempre avança no sentido de processamento da linha, e ao chegar ao último posto que é a inspeção final, existe apenas uma movimentação que não agrega valor ao produto, onde o colaborador retorna ao primeiro posto da linha de montagem. Dessa forma foi possível eliminar grande parte das movimentações não necessárias e também reduzir o percurso de caminhada dos colaboradores, fator muito importante para a motivação dos envolvidos no processo.

Outra mudança que se obteve com esse tipo de arranjo é que o colaborador que antes trabalhava em apenas um, dois, ou três processos, passa a trabalhar em todos os processos. No início ocorreram muitas dificuldades e isso exigiu um tempo de treinamento e adaptação dos operadores ao novo arranjo, por outro lado, se conseguiu colaboradores multifuncionais. Aliado a isso, o novo arranjo proporcionou uma flexibilidade em relação a demanda dos clientes que, caso houver aumento ou redução, permite adequar a quantidade de colaboradores envolvidos no processo, sem aumentar a movimentação desnecessária, visto que todos os operadores passaram a realizar todas as operações, ou seja, eliminou-se a necessidade de se fazer a redistribuição das atividades.

Aproveitou-se também para diminuir o espaço dos postos da Montagem II e da Montagem III, encurtando, desta forma, a distância percorrida pelos operadores. Esta ideia de redução no espaço entre as máquinas foi sugerida pelos próprios colaboradores envolvidos no processo produtivo.

\subsection{Análise dos resultados}

Após a alteração do arranjo físico, foi necessário fazer a confirmação dos resultados e o método para essa verificação foi utilizar novamente a ferramenta de análise de perdas, conforme Quadro 2. É possível observar que os tempos de movimentaç̃os reduziram quando comparado a situação anterior à melhoria, e a distribuição de atividades entre os operadores ficou balanceada, visto que todos passaram a realizar a mesma atividade, independentemente da quantidade de pessoas na linha de montagem. Com os resultados obtidos através dessas melhorias, criou-se um processo mais estável e mais competitivo. 
Research, Society and Development, v. 10, n. 16, e124101623403, 2021

(CC BY 4.0) | ISSN 2525-3409 | DOI: http://dx.doi.org/10.33448/rsd-v10i16.23403

Quadro 2 - Ferramenta de análise de perdas em arranjo físico em U.

\begin{tabular}{|c|c|c|c|c|c|}
\hline \multicolumn{6}{|c|}{ Folha de Distribuição Padrão } \\
\hline \multicolumn{3}{|c|}{ Linha: Montagem do Produto R } & \multicolumn{3}{|c|}{$\begin{array}{l}\text { Demanda diária: } 940 \text { pcs } \\
\text { Tempo disponível: } 8,4 \mathrm{~h} \quad(30240 \mathrm{~s})\end{array}$} \\
\hline \multicolumn{2}{|c|}{ Quantidade de operadores: } & 1 & Tempo takt: & $32,2 \mathrm{~s}$ & \\
\hline \multirow{2}{*}{ Operador } & \multirow{2}{*}{ Processo } & \multirow{2}{*}{ Operação } & \multicolumn{3}{|c|}{ Tempo (segundos) } \\
\hline & & & \multicolumn{2}{|c|}{ Máquina } & Caminhada \\
\hline \multirow{31}{*}{ Operador 1} & \multirow{6}{*}{ Montagem I } & 1. Encaixar a peça $\mathrm{C} 1$ no dispositivo & 0.9 & & \\
\hline & & 2. Encaixar a peça $\mathrm{C} 2$ no dispositivo & 1.1 & & \\
\hline & & 3. Montar componentes $\mathrm{i}, \mathrm{j}$, $\mathrm{k}$ na peça $\mathrm{C} 1$ & 7.0 & & \\
\hline & & 4. Montar componentes $1, \mathrm{~m}, \mathrm{n}$ na peça $\mathrm{C} 2$ & 8.3 & & \\
\hline & & 5. Inserir componente $\mathrm{T} 1$ & 1.7 & & \\
\hline & & 6. Retirar a peça montada do dis positivo & 0.9 & & 0.8 \\
\hline & \multirow{5}{*}{ Montagem II } & 1. Encaixar a peça G1 no dispositivo & 0.8 & & \\
\hline & & 2. Inserir os componentes $\mathrm{i}, \mathrm{j}, \mathrm{k}, \mathrm{l}, \mathrm{m}$ na peça $\mathrm{G} 1$ & 2.2 & & \\
\hline & & 3. Acionar alavanca do dispositivo & 0.8 & 1.1 & \\
\hline & & 4. Retirar a peça montada do dispositivo & 0.9 & & \\
\hline & & 5. Ins erir componente $\mathrm{T} 2$ & 0.6 & & 0.6 \\
\hline & \multirow{4}{*}{ Montagem III } & 1. Encaixar a peça G2 no dispositivo & 0.8 & & \\
\hline & & 2. Inserir os componentes $\mathrm{i}, \mathrm{j}, \mathrm{k}, \mathrm{l}, \mathrm{m}$ na peça $\mathrm{G} 2$ & 1.7 & & \\
\hline & & 3. Acionar alavanca do dispositivo & 0.8 & 1.1 & \\
\hline & & 4. Retirar a peça montada do dis positivo & 0.9 & & 0.8 \\
\hline & \multirow{6}{*}{ Montagem IV } & 1. Montar componente T3 no componente $\mathrm{n}$ & 0.9 & & \\
\hline & & 2. Montar peça R no componente $\mathrm{n}$ & 2.0 & & \\
\hline & & 3. Colocar a peça montada no dispositivo & 0.8 & & \\
\hline & & 4. Prensar componente y & & 1.0 & \\
\hline & & 5. Retirar a peça montada do dispositivo & 0.9 & & \\
\hline & & 6. Ajustar posição da peça $\mathrm{R}$ & 0.8 & & 0.8 \\
\hline & \multirow{4}{*}{ Montagem V } & 1. Ajustar posição das peças G1 e G2 & 7.1 & & \\
\hline & & 2. Aplicar componente f & 4.8 & & \\
\hline & & 3. Inserir componente $\mathrm{T} 4$ & 0.9 & & \\
\hline & & 4. Inserir componente $\mathrm{T} 5$ & 0.8 & & 1.0 \\
\hline & \multirow{6}{*}{$\begin{array}{c}\text { Inspeção } \\
\text { Final }\end{array}$} & 1. Encaixar peça no dispositivo & 0.8 & & \\
\hline & & 2. Conectar os componentes $\mathrm{i}, \mathrm{j}, \mathrm{k}$ no dispositivo & 1.0 & & \\
\hline & & 3. Realizar o teste & & 0.8 & \\
\hline & & 4. Conectar os componentes $1, \mathrm{~m}$ no dispositivo & 0.8 & & \\
\hline & & 5. Realizar o teste & & 0.8 & \\
\hline & & 6. Retirar a peça do dispositivo & 0.8 & & 1.2 \\
\hline
\end{tabular}

Fonte: Autores.

Outro importante resultado obtido foi a redução das movimentações que não agregam valor ao produto, de aproximadamente $30 \%$ em relação a situação antes da alteração. É possível perceber esta redução comparando as movimentações antes e após a alteração, tendo como referência o tempo de caminhada, conforme mostrado na ferramenta de análise de perdas acima. Além disso, grande parte das movimentações que passaram a existir após alteração do arranjo físico, são movimentações necessárias, ou seja, transportando peça.

Como consequência dessa redução na movimentação, foi possível obter também uma melhoria no balanceamento do processo, que permitiu um aumento da produtividade por pessoa, conforme mostrado na Figura 5. Com este aumento, é possível atender a demanda dos clientes com apenas 2 colaboradores, reduzindo a ociosidade do processo produtivo que existia antes da alteração. 
Figura 5 - Produtividade após a alteração.

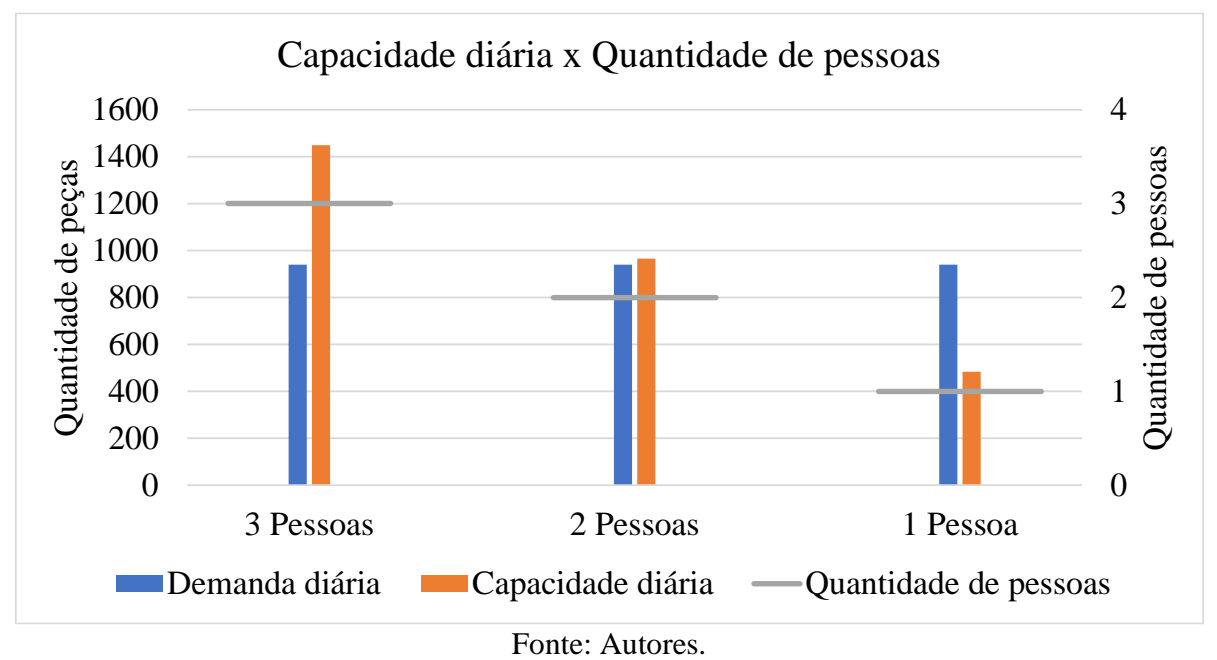

Na Figura 5 observou-se que, além da redução de quantidade de pessoas para atendimento da demanda dos clientes, houve também uma redução na ociosidade do processo, e ainda, um aumento de produtividade por pessoa em aproximadamente 6\%. Com esses dados, foi possível ratificar a melhoria no processo produtivo levando em consideração fatores como linha flexível, balanceamento do processo e aumento de produtividade.

Outro ponto importante para se destacar é em relação à qualidade. O fato de o mesmo colaborador executar as atividades desde a montagem até a inspeção final, inicialmente foi considerado um ponto negativo, já que o trabalho executado por um colaborador não será checado por outra pessoa, diminuindo as chances de detecção de defeito. Por outro lado, o fato de o colaborador saber que o produto montado por ele não passa por inspeção de outras pessoas, fez com que aumentasse o sentimento de responsabilidade e comprometimento, forçando-o a realizar as tarefas com mais atenção e cuidado. Além disso, os colaboradores passaram a ser multifuncionais e isso a longo prazo, foi um fator positivo para a qualidade do produto, pois os colaboradores tem o conhecimento de todos os processos e conhecem o impacto de seu trabalho sobre o produto final.

Com todos os benefícios obtidos após a alteração do arranjo físico, constatou-se a eficácia da utilização da ferramenta de análise de perdas, onde o processo produtivo tornou-se mais enxuto, com maior produtividade e nível de qualidade mais elevado, e principalmente, com maior flexibilidade, tornando a linha de montagem preparada para absorver qualquer tipo de variação nas demandas dos clientes.

\section{Considerações Finais}

Através do estudo realizado na linha de montagem em questão, foi possível ter conhecimento da situação atual e identificar os problemas que impactavam negativamente o processo produtivo. Com a utilização da ferramenta de identificação de perdas, foi possível propor melhorias no arranjo físico da linha de montagem, e a identificação dos principais méritos da atividade após a implantação das melhorias. Com relação aos resultados encontrados após a alteração no arranjo físico, podemos destacar a redução de aproximadamente $30 \%$ na movimentação dos colaboradores do processo, principalmente das movimentações que não agregavam valor ao produto, um aumento de $6 \%$ na produtividade por pessoa, o que possibilitou a redução no número de operadores necessários para atendimento da demanda, que passou de 3 para 2 operadores, e o ganho de flexibilidade da linha de montagem para se adequar facilmente a variação da demanda dos clientes.

É importante destacar também que a alteração no arranjo físico da linha de montagem permitiu desenvolver colaboradores multifuncionais, contribuindo para a melhoria de qualidade do processo, e ainda, para o aumento da motivação dos colaboradores envolvidos diretamente no processo, visto que aumentaram os seus conhecimentos sobre o processo 
produtivo e sobre o produto fabricado. Aliado a isso, foi possível estimular as atividades de melhoria no processo, visto que, como os operadores passaram a executar uma variedade maior de operações, eles têm maior conhecimento em relação ao produto e ao processo, estimulando o surgimento de ideias de melhorias.

Finalmente deve-se salientar os benefícios obtidos pela empresa em questão, que passou a ter uma linha de montagem com menos desperdícios, e automaticamente um processo de montagem mais competitivo em um mercado que a cada ano se torna mais seletivo.

Como limitação do presente estudo, podemos destacar o espaço amostral onde foi realizada a melhoria. Para aumentar a confiabilidade dos resultados obtidos, é interessante fazer abrangência deste estudo para as demais linhas de montagem, e assim aumentar a motivação e o conhecimento de mais colaboradores, além do aumento de produtividade e flexibilidade nos demais processos.

Como sugestões futuras, recomenda-se fazer uma revisão deste estudo, reavaliando o processo em busca de novas oportunidades de melhorias que não tenham sido identificadas no presente trabalho, aplicando também outras ferramentas da produção enxuta, aliadas às ferramentas que foram utilizadas no presente trabalho, tendo assim um estudo mais completo.

\section{Referências}

Alvarez, R. R., \& Antunes, J. A. V. (2001) Takt-time: conceitos e contextualização dentro do Sistema Toyota de Produção. Gestão \& Produção, 8(1), 1-18.

Anselmo, R. B. et al. (2020) Avanço de desempenho produtivo com a implementação do trabalho padronizado em uma célula de manufatura. Revista TECNOLÓGICA, 24(nesp), 289-299.

Antunes, J. et al. (2008) Sistemas de Produção: Conceitos e Práticas para Projeto e Gestão da Produção Enxuta. Bookman.

Bellato, J. C., \& Mazzonetto, A. W. (2021) Análise da implementação de melhorias no fluxo de processo em uma empresa metalmecânica - estudo de caso. Bioenergia em revista: diálogos, 11(1), 200-220.

Coimbra, E. (2013) Kaizen in Logistics and Supply Chains. McGraw-Hill Education.

Corrêa, H. L., \& Corrêa, C. A. (2017) Administração de Produção e Operações - Manufatura e Serviços: Uma abordagem estratégica. (4a ed.) Atlas.

Dave, P. Y. (2020) The History of Lean Manufacturing by the view of Toyota-Ford. International Journal of Scientific \& Engineering Research, 11(8), 15981602 .

Fin, J. C. et al. (2017) Improvement based on standardized work: an implementation case study. Brazilian Journal of Operations \& Production Management, 14(3), 388-395.

Freitas, E. S., \& Silva, M. G. (2017) Pesquisa-ação sobre a implementação do trabalho padronizado em uma célula de manufatura de uma fábrica de tratores. Revista ESPACIOS, 38(46), 21-37.

Lean Enterprise Institute. (2011) Léxico Lean: glossário ilustrado para praticantes do pensamento lean. (5a ed.) Lean Institute Brasil.

Liker, J. K. (2005) O Modelo Toyota: 14 princípios de gestão do maior fabricante do mundo. Bookman.

Liker, J. K., \& Meier, D. (2007) O Modelo Toyota: Manual de aplicação - Um guia prático para a implementação dos 4Ps da Toyota.: Bookman.

Marconi, M. A., \& Lakatos, E. M. (1999) Técnicas de pesquisa. (4a ed.) Atlas.

Oliveira, R. P. et al. (2017) Lean manufacturing em associação à automação industrial: Estudo de caso aplicado à indústria moveleira. Revista ESPACIOS, $38(17), 24-39$.

Oliveira, U. R., \& Figueiredo, O. C. (2018) O impacto da padronização dos desperdícios em uma indústria de autopeças. Revista Brasileira de Administração Científica, 9(1), 115-126.

Pinto, J. P. (2014) Pensamento Lean: a filosofia das organizações vencedoras. (6a ed.) Lisboa: Lidel.

Santos, B. A. P., \& Volante, C. R. (2020) Proposta de readequação de arranjo físico na indústria têxtil: um estudo de caso na linha de produção de confecção de roupas. Revista Interface Tecnológica, 17(1), 590-602.

Shingo, S. (2005) O Sistema Toyota de Produção do ponto de vista da Engenharia de Produção. Bookman.

Silva, C. C. M. et al. (2019) Aplicação de ferramentas da manufatura enxuta: um estudo de caso em uma fábrica de colchões. Journal of Lean Systems, 4(1), 87-104.

Slack, N., Chambers, S., \& Johnson, R. (2009) Administração da Produção. (3a ed.) Atlas. 
Research, Society and Development, v. 10, n. 16, e124101623403, 2021

(CC BY 4.0) | ISSN 2525-3409 | DOI: http://dx.doi.org/10.33448/rsd-v10i16.23403

Suri, R. (1998) Quick Response Manufacturing: a companywide approach to reducing lead times. Portland: Productivity Press.

Suzaki, K. (1987) The New Manufacturing Challenge: techniques for continuous improvement. The Free Press.

Trentin, L. (2017) Manufatura enxuta: Contribuições para a obtenção da vantagem competitiva. Revista ESPACIOS, 38(9), 6-14.

Vergara, S. C. (2000) Projetos e relatórios de pesquisa em administração. (3a ed.) Atlas.

Womack, J. P., Jones, D. T., \& Roos, D. (1992) A Máquina que mudou o mundo. (5a ed.) Campus.

Womack, J. P., Jones, D. T. (2003) Lean Thinking: banish waste and create wealth in your corporation. Simon \& Schuster, Inc.

Yamamoto, K., Milstead, M., \& Lloyd, R. (2019) A Review of the Development of Lean Manufacturing and Related Lean Practices: The Case of Toyota Production System and Managerial Thinking. International Management Review, 15(2), 21-40. 